\title{
Setting a Cap on the Maximum Average Number of Drinks Per Day in Australian Survey Research
}

\author{
Sarah Callinan ${ }^{1}$ \\ ${ }^{1}$ La Trobe University, Centre for Alcohol Policy Research, Bundoora, Australia
}

\begin{abstract}
Aims: The aim of this study is to assess the impact of the cap level on total consumption and a range of variables including negative consequences.

Design, Setting, and Participants: Cross sectional survey in Australia with 2,020 Australians aged 16 and over.

Measures: Participants completed a detailed survey on their alcohol consumption with no methodological limit on consumption.

Findings: Setting a cap on high levels of consumption can significantly decrease the mean level of consumption. While the relationship between consumption and related variables do not change significantly, the relationship with negative consequences strengthens as the cap lowers, and the relationship with purchases decreases for uncapped data and data with low caps, providing some guidance on where a cap would be best placed.
\end{abstract}

Conclusions: Consideration of where to set a maximum daily consumption level in survey research should be not only based on what could be feasibly consumed, but also on the point at which a very high reported consumption level is more likely to have been reported in error than as a reflection of reality. Checking the relationship between consumption and related variables, with different caps applied before selecting a capping level, is recommended.

\begin{abstract}
A large portion of research into alcohol consumption is conducted with surveys where respondents report on their own consumption. An important consideration when selecting or developing a measure of alcohol consumption is at what number, if any, the maximum of number of drinks consumed per day will be capped. When open-ended responses about alcohol consumption are allowed, some responses-say, two liters of ethanol per day-will presumably be made in error. However, there is a range in which the plausibility of a high level of reported consumption is not clear. Ledermann assumed that the number of people in any given population drinking a liter of ethanol a day would be constant, effectively zero, regardless of the drinking pattern within a population (Ledermann, 1956). Importantly, there is a difference between the maximum amount someone could drink in one day, and the maximum amount that person could consume on average over a longer reference period, say six months or a year (Greenfield \& Kerr, 2008). Skog (1993) notes that the proportion of the population drinking above even 150 liters
\end{abstract}

per year (approximately $320 \mathrm{~g}$ per day) would be negligible, as this would be a level of consumption that would be difficult to keep up over a long amount of time. However, $320 \mathrm{~g}$ in one day is a very plausible figure for consumption.

Large reported levels of consumption are not only concerning on the grounds of accuracy in measurement; as outliers they will also have an outsize influence on many analyses. A popular way of addressing this issue is to place a cap on consumption. In this practice, any figure over a given level is recoded as that same value. By doing this, these high figures will not have an undue impact on analyses, while the high consumption of the individual is still acknowledged in analyses. However, little information or guidance is available on the appropriate level at which a cap should be placed. Place a cap too high and analyses can be unduly influenced by high figures reported in error; place it too low and consumption will be underestimated. The common practice of capping consumption at $150 \mathrm{~g}$ of alcohol per day could be responsible for underestimation of not only

Correspondence: Sarah Callinan, PhD, La Trobe University Centre for Alcohol Policy Research, Bundoora, VIC, 3086 Australia. Phone: +613 9479 8739, Email: s.callinan@latrobe.edu.au

Financial support: The data used in this paper are from the Australian arm of the International Alcohol Control Study (IAC), led by Professor Sally Casswell. The IAC core survey questionnaire was largely developed by researchers at SHORE \& Whariki Research Centre, College of Health, Massey University, New Zealand, with funding from the Health Promotion Agency, New Zealand. Further development involved collaboration between UK, Thai, Korean, and New Zealand researchers. The funding source for the data set used in this article is the Australian National Preventive Health Agency (ANPHA; grant ref 157ROO2011). The contents of this paper are solely the responsibility of the author and do not reflect the views of ANPHA. The author's time on this study was funded by the Australian Research Council (DE180100016).

Declaration of interest: The authors declare that they have no competing financial or other interests.

Keywords: alcohol, survey research, methodology 
consumption but also alcohol-attributable mortality in burden of disease studies (Gmel, Shield, Kehoe-Chan, \& Rehm, 2013). Therefore, this is a methodological issue that may have an impact on important research around the world that plays a major role in policy decisions.

A survey that allows for unlimited reports of consumption is required to assess what, if any, level is an appropriate level of daily consumption at which a cap should be placed. The beverage-specific, location-based loops used in the International Alcohol Control Study tend to elicit higher levels of consumption that line up better with sales data than other, less time-consuming survey methods (Livingston \& Callinan, 2015). Given the impact of capping on interpretation of research on alcohol consumption, the aim of the current study is to use data from the Australian arm of the International Alcohol Control (IAC) study to investigate the impact of capping level on total consumption and relationships between consumption, purchasing, and harm. The focus will be on identifying the point at which a cap is most effective at differentiating between genuine high levels of consumption and those made in error. A key assumption of this analysis is that a more accurate measure of alcohol will be a better predictor of alcohol-related harms than a poorer alternative (Greenfield, 1998). The current study will assess the relationship between total alcohol volume consumed and negative consequences, purchasing, and demographics.

\section{Method}

\section{Sample}

Data were obtained from the Australian arm of the IAC study, conducted in 2013. The questionnaire was adapted from the New Zealand IAC survey (Casswell, Huckle, \& Pledger, 2002). Computer-assisted telephone interviews were conducted with a sample collected using probabilistic sampling methods in conjunction with random-digit dialing in a dual-frame sample, with $60 \%$ of the sample recruited via landline and $40 \%$ via mobile phone. Risky drinkers (who consumed $\geq 50 \mathrm{~g}$ in an occasion, at least once a month) were oversampled; only one third of those who did not meet this criterion (i.e., abstainers or lower-level drinkers) were asked to complete the survey. This resulted in a higher number of respondents of particular interest in the current study, while still allowing representative statistics to be developed when weights correcting for this are applied. A total of 2,020 people aged 16 and older from across Australia agreed to participate in the study, with a response rate by the standards of the American Association for Public Opinion Research (2008) of $37.2 \%$. Data are taken from the 1,789 respondents who consumed alcohol in the past year, $59.6 \%$ male, with a mean age of 43.7 years $(S D=17.0)$. Survey questions relevant to the current study are outlined below; for a more detailed description of the survey methods please see the technical report (Jiang, Callinan, \& Room, 2014).

\section{Survey}

All respondents, aside from abstainers, were asked a series of survey items within beverage-specific location-based loops to measure their alcohol consumption. As part of these loops, respondents were asked how often they drank at a number of distinct types of location, be they on-premise locations (pubs, clubs, restaurants, and special events) or offpremise locations (own home, someone else's home, workplace, or a public space). The category of pubs also includes taverns, nightclubs, and hotels, while the category of clubs includes sporting clubs and social clubs such as the Returned and Services League of Australia. Special events include but are not limited to events focused on sport and music. All of these distinctions were made clear to respondents. The reference period for these questions was six months.

For each drinking location, respondents were asked, concerning a usual occasion at that location, what drink types, and how many of each of these drink types, they consumed. Respondents could give their usual consumption levels in whatever units they consumed each drink in - for instance, they could say they drank six "stubbies" of regularstrength beer, rather than being expected to know that this is approximately $84 \mathrm{~g}$ of ethyl alcohol (Casswell et al., 2002). This method results in higher reported consumption (nearly $90 \%$ of sales accounted for) than more commonly used methods such as graduated frequency (40-60\%) (Livingston \& Callinan, 2015).

Respondents were also asked their experience of negative consequences experienced from drinking: "Has your drinking had a harmful effect on your work, study, or employment opportunities/ marriage or intimate relationships/ relationships with other family members/ friendships or social life/ physical health?" These items were used to get a score out of six, representing number of negative consequences experienced. Detailed questions on alcohol purchases to consume elsewhere, referred to as "offpremise alcohol," allowed for an average price per standard drink to be calculated per respondent.

Data sets were saved with a maximum average daily consumption capped at 150,210, 300, 400, and 500 grams, and finally with uncapped data consumption. When applying a cap-for example, $150 \mathrm{~g}$ - any average reported consumption over $150 \mathrm{~g}$ per day were adjusted to $150 \mathrm{~g}$ per day. The $150 \mathrm{~g}$ cut-off was selected as it is a commonly used cap in medical research examining alcohol-attributable fractions (e.g., Shield, Taylor, Kehoe, Patra, \& Rehm, 2012; Jones \& Bellis, 2013). The $210 \mathrm{~g}$ cap was selected because it is often the amount assumed when people report " $200 \mathrm{~g}$ or more" (e.g., Stockwell et al., 2004; Livingston \& Callinan, 2015). The caps of 300,400 , and $500 \mathrm{~g}$ were selected arbitrarily.

\section{Data Analysis}

All analyses conducted below are conducted on all six data sets. Data analysis was conducted using Stata version 13. Multiple linear regression models predicting experience of negative consequences and off-premise purchasing with total volume consumed as a predictor, controlling for age and sex, were run. Models predicting total volume consumed using demographic variables as predictors were also run. Confidence intervals (CIs) were used to identify significant 
differences between odds ratios, with non-overlapping CIs indicating significant differences in estimates.

\section{Results}

The mean amount of alcohol consumed at each capping level, along with the proportion of the sample that is above each level, is shown in Table 1. Mean consumption did increase somewhat as the capping level rose. Notably, this apparent increase is attributable to a very small proportion of drinkers, indicating the outsize impact that these higher responses might be having on analyses. To investigate the relationship between consumption and negative consequences from drinking, regression coefficients predicting negative consequences with the different cap levels is shown in Table 2. There appears to be a trend where the relationship between total volume consumed and negative consequences experienced because of alcohol consumption gets weaker as the cap is lifted. However, the relationship between off-premise purchasing and consumption peaked between 300 and $500 \mathrm{~g}$ per day, albeit with no significant differences between coefficients. Finally, the mean number of harms experienced by people who reported consumption above each of the cap levels was calculated. People who reported an average consumption of more than 400 or $500 \mathrm{~g}$ per day appeared to experience less harms from their consumption, possibly because these high levels of consumption were reported in error. While it is important to acknowledge the demographics of the individuals reporting over each cap level may be confounding these results, one would assume that harms would be high at the highest drinking levels regardless of personal circumstances.

To further investigate the impact of capping on relationships between total volume and basic demographic variables, regression models were run predicting standardized total volume scores with changing capping levels (Table 3). Total volume at each capping level was standardized so that the regression coefficients could be compared. The relationship between gender and total volume weakened as the cap level rose, although it did stay significant.

\section{Table 1}

Mean grams of alcohol consumed per day at each

\begin{tabular}{ccc}
$\begin{array}{c}\text { capping level } \\
\text { Cap level }\end{array}$ & Mean g/day (95\% CI) & \% over each level \\
\hline $150 \mathrm{~g}$ & $17.8[16.2,19.4]$ & $2.1 \%$ \\
$210 \mathrm{~g}$ & $18.9[17.1,20.8]$ & $1.0 \%$ \\
$300 \mathrm{~g}$ & $19.7[17.7,21.7]$ & $0.3 \%$ \\
$400 \mathrm{~g}$ & $20.0[18.0,22.1]$ & $0.2 \%$ \\
$500 \mathrm{~g}$ & $20.2[18.1,22.4]$ & $0.2 \%$ \\
uncapped & $20.7[18.3,23.1]$ & N/A \\
\hline
\end{tabular}

Table 2

Regression coefficients predicting total volume consumed at multiple cap levels using related and demographic variables

\begin{tabular}{|c|c|c|c|c|c|c|}
\hline & \multicolumn{6}{|c|}{ Cap Level } \\
\hline & $\begin{array}{l}150 \mathrm{~g} / \text { day } \\
(95 \% \mathrm{CI})\end{array}$ & $\begin{array}{l}210 \mathrm{~g} / \text { day } \\
(95 \% \mathrm{CI})\end{array}$ & $\begin{array}{l}300 \mathrm{~g} / \text { day } \\
(95 \% \mathrm{CI})\end{array}$ & $\begin{array}{l}400 \mathrm{~g} / \text { day } \\
(95 \% \mathrm{CI})\end{array}$ & $\begin{array}{l}500 \mathrm{~g} / \text { day } \\
(95 \% \mathrm{CI})\end{array}$ & $\begin{array}{l}\text { uncapped } \\
(95 \% \text { CI })\end{array}$ \\
\hline $\begin{array}{l}\text { Beta coefficient of negative } \\
\text { consequences predicting total } \\
\text { volume consumed }\end{array}$ & $\begin{array}{c}0.41 \\
{[0.31,0.50]}\end{array}$ & $\begin{array}{c}0.41 \\
{[0.30,0.51]}\end{array}$ & $\begin{array}{c}0.40 \\
{[0.29,0.52]}\end{array}$ & $\begin{array}{c}0.38 \\
{[0.27,0.50]}\end{array}$ & $\begin{array}{c}0.37 \\
{[0.27,0.48]}\end{array}$ & $\begin{array}{c}0.35 \\
{[0.25,0.45]}\end{array}$ \\
\hline $\begin{array}{l}\text { Beta coefficient of off-premise } \\
\text { purchasing predicting total } \\
\text { volume consumed off premise }\end{array}$ & $\begin{array}{c}0.67 \\
{[0.47,0.87]}\end{array}$ & $\begin{array}{c}0.72 \\
{[0.53,90]}\end{array}$ & $\begin{array}{c}0.74 \\
{[0.56,0.93]}\end{array}$ & $\begin{array}{c}0.74 \\
{[0.54,0.95]}\end{array}$ & $\begin{array}{c}0.74 \\
{[0.52,0.97]}\end{array}$ & $\begin{array}{c}0.71 \\
{[0.47,0.96]}\end{array}$ \\
\hline $\begin{array}{l}\text { Mean number of harms for those } \\
\text { above each cap level }\end{array}$ & $\begin{array}{c}1.23 \\
{[0.89,1.58]}\end{array}$ & $\begin{array}{c}1.28 \\
{[0.70,1.85]}\end{array}$ & $\begin{array}{c}1.08 \\
{[0.34,1.83]}\end{array}$ & $\begin{array}{c}0.85 \\
{[0.35,1.37]}\end{array}$ & $\begin{array}{c}0.75 \\
{[0.26,1.24]}\end{array}$ & N/A \\
\hline
\end{tabular}

Note. Beta coefficients from multiple regression models controlling for age and gender 
Table 3

Regression models predicting a standardized measure of grams of alcohol consumed per day with different cap levels applied $(N=1,789)$

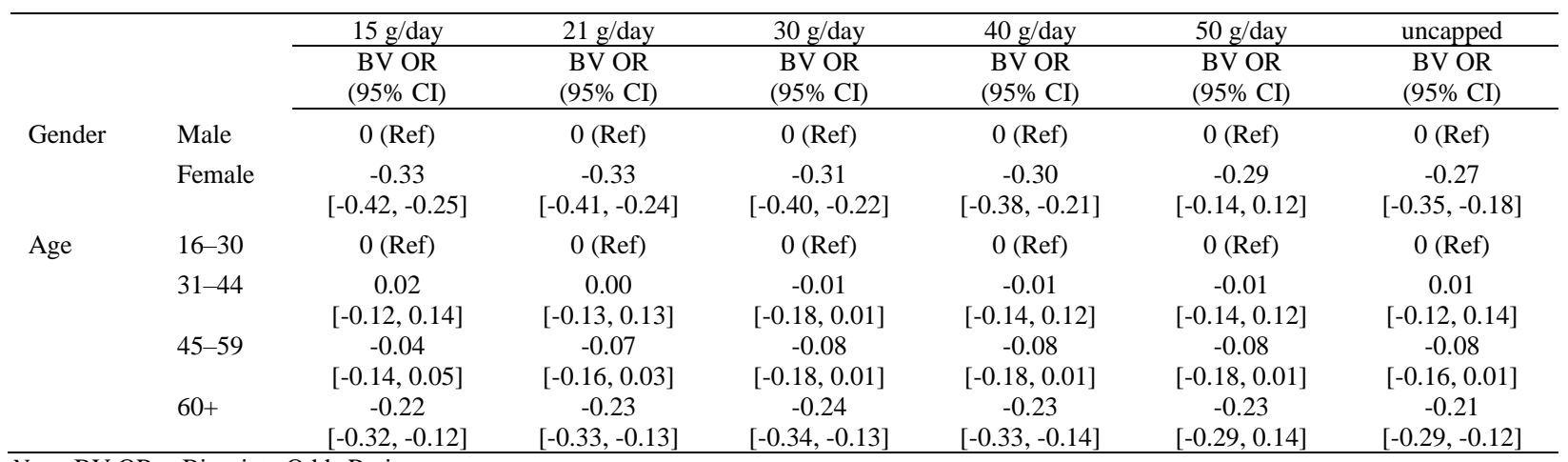

Note. $\mathrm{BV}$ OR $=$ Bivariate Odds Ratio

\section{Discussion}

As expected, mean consumption levels are significantly affected by caps applied to the heaviest drinkers. While the level of capping does not have a significant impact on the relationship between total volume consumed and demographics, negative consequences, and purchasing, there were indications that uncapped data and, to a lesser extent, data cleaned with higher caps were making a difference. There were non-significant decreases in the relationship between consumption and negative consequences as cap levels increased, while the relationship between consumption and purchasing appeared to peak between $300 \mathrm{~g}$ and $500 \mathrm{~g}$ per day.

When interpreting these results it is important to remember that the cap levels here are representing daily average drinking over a six-month period, not heavy consumption on single occasions. That is, the question here is not how much could a person could consume in one day, but rather what is a plausible average daily consumption over a long period of time? Our results suggest that for this survey, with a sixmonth reference period, reported average daily consumption over $300 \mathrm{~g}$, or even $210 \mathrm{~g}$ per day, are increasingly likely to be made in error. In particular, the relationship between consumption and harm seemed to weaken for those respondents who reported more than $500 \mathrm{~g}$ of consumption per day. While there do seem to be non-significant trends in the relationship between consumption and harms as caps on consumption are adjusted, it is also worth noting that ultimately, the relationship between total volume and a range of other variables in bivariate and multivariate models did not shift greatly, at least between $150 \mathrm{~g}$ and $300 \mathrm{~g}$ per day.

The results presented in this study have the same limitations of all studies with self-reported survey data. While the errors inherent to this are the focus of the study, the attempt to identify these errors has been based on other self-reported data such as negative consequences from drinking and offpremise purchasing. Furthermore, the sample size of respondents reporting high levels of consumption decreased as the cap level of interest decreased. Finally, as is common in survey research in Australia and many other high-income countries, the response rate for this survey was low, and representation of the entire population cannot be assumed. As such, all caution in interpreting results from self-reported survey data should be used with respect to the results of this study.

It is recommended that the maximum consumption level should not be solely based on what could be feasibly consumed, but the point at which a reported level of consumption is more likely to made in error than to reflect an accurate estimate of consumption. This level will presumably shift with the reference period in the survey used - in other words, plausible daily consumption over a day or a week would presumably be higher than plausible daily consumption over six or twelve months. Caps are regularly placed on reported levels of alcohol consumption in a wide range of studies; however, there appears to be little thought given, at least as evidenced in published research, as to where that cap should be placed or what the impact of these caps might be on the accuracy of measurement. This paper will hopefully provide some guidance on this issue. While the analyses presented here are specific to an Australian context and a particular survey type, checking the relationship of consumption with variables known to correlate with consumption to find an appropriate cap level would be a judicious course of action regardless of context or survey. Such analyses will hopefully reduce the impact of capping on not only estimates of consumption but also the contribution of alcohol to the global burden of disease.

\section{References}

American Association for Public Opinion Research. (2008). Standard definitions: Final dispositions of case codes and outcome rates for surveys. Lenexa, Kansas: American Association for Public Opinion Research.

Casswell, S., Huckle, T., \& Pledger, M. (2002). Survey data need not underestimate alcohol consumption. 
Alcoholism: Clinical and Experimental Research, 26, 1561-1567.

Gmel, G., Shield, K., Kehoe-Chan, T., \& Rehm, J. (2013). The effects of capping the alcohol consumption distribution and relative risk functions on the estimated number of deaths attributable to alcohol consumption in the European Union. BMC Medical Research Methodology, 13(24), 1-9.

Greenfield, T. (1998). Evaluating competing models of alcohol-related harm. Alcoholism: Clinical and Experimental Research, 22, 52s-62s.

Greenfield, T., \& Kerr, W. C. (2008). Alcohol measurement methodology in epidemiology: Recent advances and opportunities. Addiction, 103: 1082-1099.

Jiang, H., Callinan, S., \& Room, R. (2014). Alcohol Consumption and Purchasing (ACAP) Study: Survey approach, data collection procedures and measurement of the first wave of the Australian arm of the International Alcohol Control Study. Melbourne, Australia: Centre for Alcohol Policy Research.
Jones, L., \& Bellis, M. (2013). Updating England-specific alcohol attributable fractions. Liverpool, England: Liverpool John Moores University.

Ledermann, S. (1956). Alcool, Alcoolisme, Alcoolisation. Paris, France: Presses Universitaires de France.

Livingston, M., \& Callinan, S. (2015). Under-reporting in alcohol surveys: Whose drinking is under-estimated? Journal of Studies on Alcohol and Drugs, 76, 158-164.

Shield, K. D., Taylor, B., Kehoe, T., Patra, J., \& Rehm, J. (2012). Mortality and potential years of life lost attributable to alcohol consumption in Canada in 2005. BMC Public Health, 12(1), 91.

Skog, O. (1993). The tail of the alcohol consumption distribution. Addiction, 88, 601-610.

Stockwell, T., Donath, S., Cooper-Stanbury, M., Chikritzhs, T., Catalano, P., \& Mateo, C. (2004). Under-reporting of alcohol consumption in household surveys: A comparison of quantity-frequency, graduatedfrequency and recent recall. Addiction, 99(8), 10241033. 